\title{
Substantiating operational parameters of load- haul-dumpers in the context of irregular-shaped underground mine workings
}

\author{
Leonid Shyrin ${ }^{1}$, and Ivan Iniutkin ${ }^{1^{*}}$ \\ ${ }^{1}$ National Mining University, Department of Transport Systems and Technologies, 19 Yavornytskoho \\ Ave., 49005 Dnipro, Ukraine
}

\begin{abstract}
Objective of the paper is to substantiate scientifically parameters and design of energy-efficient transportation and operational schedules for ore masses transfer by means of new-generation load-haul-dumpers (LHDs) adapted to real mining environment at different development stages. Features concerning formation of cargo traffics and components of mining as well as tunneling systems in the context of uranium deposits mining have been studied. Mathematical model to identify operational indices of load-haul-dumpers has been developed. Layout features of the spaced pin-connected frame construction have been used to develop mathematical models of disturbed motion. Potential sources to improve the efficiency of load-haul-dumpers in the context of mining intensification have been analyzed.
\end{abstract}

\section{Introduction}

In the current context of uranium deposits mining in Ukraine, previously implemented projects of their development are corrected towards phased increase in production capacities of operating ore mines at the expense of implementation of the advanced technical and process design details and systems of innovative self-propelled facilities. High economic operational performance of the world mining enterprises engaged in transportation and technological schemes mastering with the use of multi-purpose loadhaul-dumpers has been the objective factor to make such design solutions [1]. However, introduction of high-tech equipment into traditional schemes of underground transport without scientific and technological arguments for its productive use in terms of specific environment of uranium deposits makes it impossible to achieve planning variables.

First of all, that depends on the following: disproportion between performances of interdependent subsystems of underground transport arises mostly in the process of operation of diverse self-propelled facilities differing in their functional areas, designs, productivity, and energy consumption. Significant difference in performance indices of the available high-tech self-propelled facilities and those being implemented needs the improvement of traditional transportation and technological schemes as well as their

\footnotetext{
* Corresponding author: injutkin@gmail.com
} 
adaptation to the variable mine environment in the process of primary mining and stoping intensification [2].

Comparative evaluation of operation parameters of foreign-made self-propelled facilities, applied in the context of domestic enterprises, with the performance of similar equipment abroad has helped identify a number of problems being typical for enterprises applying innovative high-tech equipment. It has been determined that basic factors, restricting large-scale implementation of innovative load-haul-dumpers, are as follows: low maintenance level; lack of production diagnosing system; and imperfection of obsolete techniques to determine performance parameters of energy-intensive self-propelled facilities in terms of complicated operational environment.

Taking into account the latter, the necessity to make expert evaluation of available transportation and technological schemes for ore transfer within irregular-shaped underground mine workings has arisen as well as the necessity to carry out specific research to determine adaptation capacities of innovative LHDs in terms of gradual increase in mine output and further improvement of design solutions.

Earlier research has determined that, in terms of mining intensification, a number of mining and geological, technical, technological, and organizational factors effect the performance of self-propelled face equipment as well as formation of traffic flows from stopes and development faces. Hence, current systems of underground transport should rely upon the use of high-tech vehicles, involve maximally changes in technologies aimed at uranium extraction, and be geared to energy-and resource-saving. Fundamental difference of transportation and technological systems with the help of high-tech LHDs is that traditional schemes of ore delivery from stopes using self-closed self-propelled facilities with uncompleted bonds are replaced by multi-purpose equipment with innovative characteristics [3]. Intensification of the first mining and second mining and the use of energy-intensive vehicles under complicated mining and geological conditions need adequate scientific and research support.

In this connection, scientific and research substantiation of performance parameters of self-propelled facilities as well as the development of highly adaptive operation schedules of underground transport on the basis of high-tech LHDs under real mine conditions are topical problem which solution will improve sufficiently both energy saving and efficiency of underground uranium ore mining.

\section{Performance features of load-haul-dumpers in terms of irregular-shaped underground mine workings}

Specific conditions of uranium deposit development predetermine different alternatives concerning integration of load-haul-dumping and transportation systems. Traditional steplike schemes of underground transport used in ore mines of the industry include different types of bottom hole drilling and loading assemblies as well as site systems of loading equipment with self-propelled cars, load-haul-dumpers with load-carrying shovels and load-haul-dump machines with load-carrying bodies. In the context of main haulage road, locomotive haulage of ore mass and cargo delivery are mainly used. Application area of one or another variant of transportation-technological scheme depends upon available extraction systems and sections of load-haul and conveyor entries.

While ore mining at $480 \mathrm{~m}$ levels and deeper, design solutions of the staged plant developments involve gradual transition to transportation and technological schemes with the use of high-tech LHDs and dumpers to hoist rock mass by means of runaways. Intermediate stage of the activities involves solution of a system of interdependent multicomponent problems determining operational parameters of innovative bucket LHDs and principles of resource- and energy-saving while uranium ore mining. 
Following scientific and research problems are basic ones:

- analysis of features concerning formation of cargo flows as well as mining and tunneling systems at different stages of uranium ore deposit development;

- determination of operation parameters and stability of LHDs within irregular-shaped mine workings;

- identification and evaluation of potential sources to improve the efficiency of innovative LHDs in the context of mining intensification;

- substantiation of design parameters of transportation entries providing the efficient use of high-tech self-propelled facilities.

Idea of the paper is to substantiate scientifically operating principles, parameters and design of non-multipurpose transportation and technological schemes to develop uranium deposits relying upon the use of innovative self-propelled LHDs providing intensification of mining operations and energy-saving in the context of gradual ore development.

The objective achieving involves the problem to be solved: it is necessary to analyze parameters of a mine working-LHD transportation and technological system in the process of ore transfer within a stope and mine sites of haulage level.

Integrated research technique has been applied to solve the problems. The technique involves processing and generalizing of scientific sources concerning the object problem, carrying out of theoretical studies as well as in-mine testing of the technical solutions being developed.

Lateral stability of LHD was analyzed in the process of its motion within underground mine workings with variable hypsometry of a path. The analysis was based upon the use of mathematical modeling methods [4]. Operational parameters of a mine working-LHD technological system were determined in accordance with the results of in-mine tests of LHD indices using methods of mathematical analysis and statistics. Simulation with the use of standard software was applied to substantiate adaptation criterion of LHD and to evaluate its effect on energy-and resource-saving. The program of the experiments generalized the simulation results and calculations of actual data concerning the performance of mine transportation and technological systems in the context of different operation stages.

It should be noted that development of uranium ore deposits with the help of selfpropelled facilities unites such linked transportation and technological processes as: well drilling for ore breaking; ore mass drawing and its removing from chambers (vehicle loading and removal from a stope); its transfer to a haulage level and transportation to a shaft station with following surface haulage and delivery to a processing plant.

In the context of mining intensification, technological schemes for ore transportation rely basically on the use of LHDs manufactured by well-known world producers.

If operational practices and resource tests concerning such machines are not available, the necessity for scientific substantiation with the consideration of limiting factors and specific character of mining arises.

Specific factors of vein deposits effecting the efficiency of LHDs are characterized considerably by ore body occurrence features and a drill and blast tunneling method applied to construct both temporary and development mine workings [5]. According to a pattern for the temporary and development workings construction, drilling operations are performed through the ore body with wall rock cutting. As a result, loading-hauling mine workings are of complicated configuration, i.e. they are non-linear in the plan. Processing of statistic data on the changes in the direction of the mine workings under construction has shown that probable variations of their dynamic axis within $15^{\circ}$ in terms of sites with 50 lengths are 90-95\%. Fig. 1 demonstrates actual profile and a plan of a development mine working constructed by means of drill and blast tunneling method under mining and geological conditions of "Smolinska" mine. 


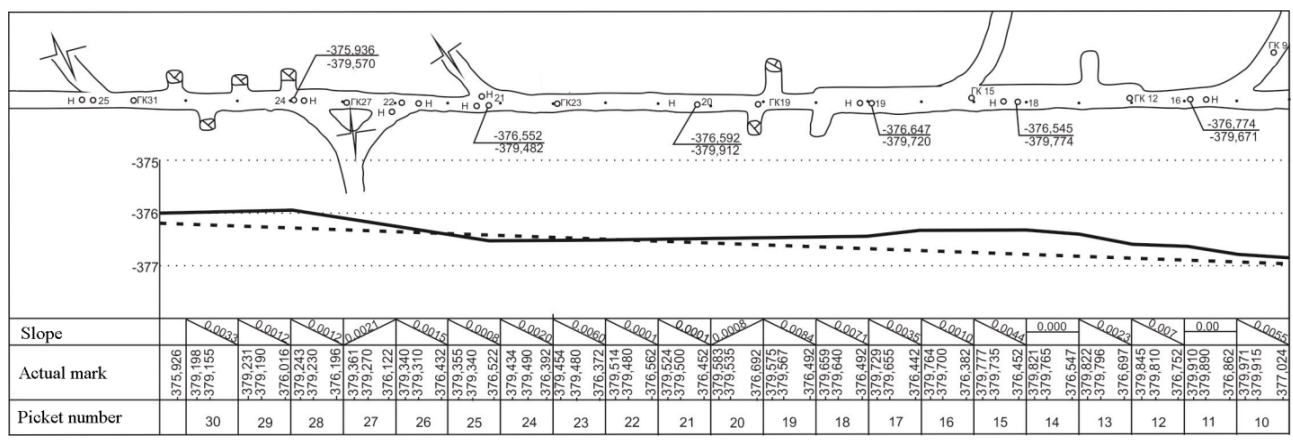

Fig. 1. Actual profile and a plan of haulage mine working constructed by means of drill and blast tunneling method.

Underground investigations have helped determine that changes in direction and floor profile of loading-haulage and development mine workings as well as ground roughness and road covering quality effect significantly the technical state and operation parameters of LHDs. To evaluate operational parameters of LHD performance, track profile of its advance from loading point to ore passageway was divided into typical sections within orepassageway level, on the decline and level haulage mine workings. Longitudinal vibration (galloping) and limiting values of LHD body lateral deviation as for the design axis, resulting in deformation of metal structures, redistribution of loads applied for semi-frame, and deceleration, have been registered in the process of the self-propelled facilities motion within haulage mine workings [6]. The research data have demonstrated that efficiency of high cost of energy-consuming innovative LHDs is supported by high velocities, minimum unproductive time during a shift, and corresponding service level.

Thus, substantiation of such rational energy parameters of a bucket LHD as the increased pressure while ore mass loading, movement velocity and time (both with load and without it) involved coordination quantitative and qualitative indices determining interaction of a mine working- $L H D$ transportation and technological scheme. Analysis of parameters of the system components interaction involved consideration of following factors: soil status and slopes of mine workings within a zone of ore mass loading; ratio of oversize yield (i.e. more than $1000 \mathrm{~mm}$ ); distance form a stope to ore drawing; section of haulage mine workings; length of slopes and rises within the path; irregularities of floor and walls of haulage mine working; availability of side tracks etc. Research [7] has determined that effect of the parameters on innovative LHD performance is demonstrated specifically when it performs operations aimed at ore mass loading, haulage, and dumping to ore passageway. Such mining factors as thickness and slope angle of ore bodies, stability of wall rocks as well as parameters of extraction technique being applied and its components determine specific cost to carry out the processes. It should also be noted that while forming technological schemes for ore transportation, drilling and blasting parameters, a technique for the broken ore drawing, geometry of sub-standard ore fragments as well as methods of their secondary crushing are significant too. According to recommendations, oversize yield and optimum value of the fragment average dimension should be determined according to the criterion of minimum expenditures connected with drilling and blasting operations and delivery. Taking into consideration the fact that drilling and blasting operations parameters also identify section, shape, and operating conditions of haulage mine workings, indices of explosion effect upon interaction conditions of mine workingLHD transportation and technological system should also be taken into consideration. Up till now, such research has not been carried out. 
Earlier studies have proved that increase in the delivery distance decreases the efficiency of self-propelled facilities; however, the fact is controversial since a type of a path and its state predetermine the machine velocity as well as its efficiency [8]. It depends on the following: on short paths, a vehicle cannot produce high velocity since it should accelerate and break; average speed is higher in the context of longer paths. Average velocity decreases on the irregular-shaped path due to the necessity of frequent maneuvering. Moreover, the facilities operate more efficiently within horizontal mine workings to compare with up-hill motion or down-hill one. The world practices concerning performance of such LHDs confirm: their velocity is much higher if a floor is leveled or surfacing (i.e. chippings, bitumen concrete, or concrete) is available. At the same time, such activities involve extra charges; thus, their expediency should be substantiated by means of feasibility analysis.

In this context, while performing a design process of high-adaptive systems of selfpropelled facilities to extract and deliver ore under real conditions of mining, each enterprise should solve problems of optimum ratio between drilling and blasting operations, operational parameters of LHDs, and parameters of haulage mine workings.

\section{Results of mathematical modeling of operational parameters of LHDs}

In the context of world practices, current technological schemes of ore delivery by means of self-propelled facilities rely upon the use of either bucket LHDs or dumper-LHD systems [9]. In this case, the self-propelled machines as well as their systems are used to load ore mass from open face floor and from bottom ore drawing and sublevel ore drawing from special mine workings.

Generally, frame of pneumatic-tired LHD has two-sectional design variant and two pinconnected joints. One pin has vertical axis providing the frame horizontal articulation; another pin involves vertical axis making it possible to perform mutual transverse turn of the section.

Possible stability loss within transverse plane of each section independently of one another is characteristic feature of the pin-connected machines. It results from the availability of feathering hinge and mutual arrangement of two pin-connected joints.

As it is known [10], a design with the spaced vertical and horizontal hinges is rational for pneumatic-tired LHDs. In this case, ladling mechanism is in an assembly section in turn being mounted on the front axle either with rigid suspension or with flexible one. A body is mounted on a balancing bridge.

Below you can find calculations of allowable velocity of pneumatic-tire LHDs with the achievement of their operational parameters as well as typical dimensions of a mine working.

Characteristic feature of LHD is as follows: having spaced pin-connected joints, it can vibrate progressively within transverse plane relatively to longitudinal axis passing through feathering hinge. Fig. 2 demonstrates calculation model of a load-haul-dumper (front view).

Consider that kinematic perturbations act only from the right forehand in the direction of a load-haul-dumper travel. Perturbation equation is obtained in the form of Lagrange's equation of second kind [11]:

$$
E_{K}=\frac{d}{d t}\left(\frac{d E_{K}}{d \dot{q}_{j}}\right)-\frac{d E_{K}}{d \dot{q}_{j}}=\frac{d E_{P}}{d \dot{q}_{j}}+Q_{j},
$$


where $E_{K}$ is kinetic energy of the system, $\mathrm{J} ; E_{P}$ is potential energy of the system, $\mathrm{J} ; \dot{q}_{j}$ is generalized coordinate, $\mathrm{m}(\mathrm{rad}) ; Q_{j}$ is generalized force of nonconservative origin, $\mathrm{N}(\mathrm{H} \cdot \mathrm{m})$.

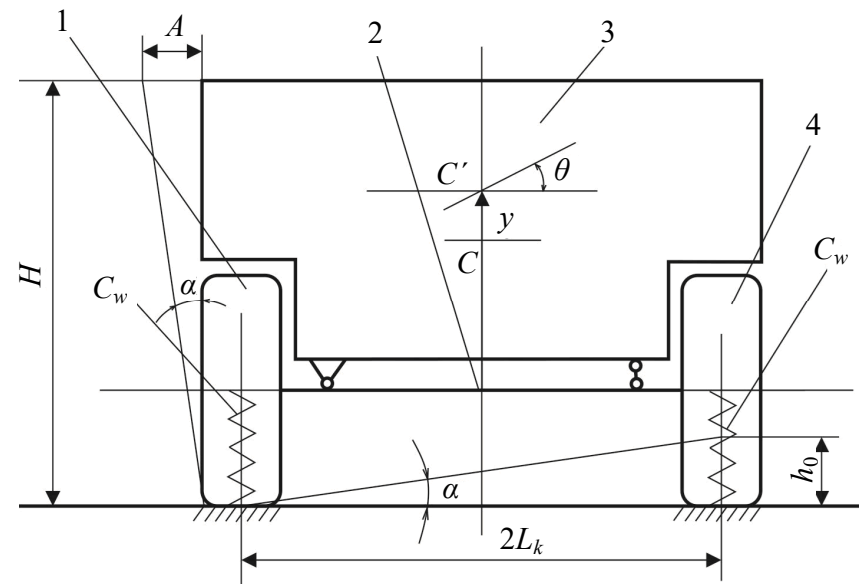

Fig. 2. Calculation model of a load-haul-dumper (front view): 1 - right wheel; 2 - continuous bridge; 3 - body; and 4 - left wheel.

In this case, $\dot{q}_{1}=y, \dot{q}_{2}=\theta$ where $y$ is vertical displacement of the system mass centre, and $\theta$ is turning angle of a machine within transverse plane.

Kinetic energy of the system is:

$$
E_{K}=\frac{m_{c} \dot{y}^{2}}{2}+\frac{I_{c} \dot{\theta}^{2}}{2}+\frac{m_{c} v^{2}}{2},
$$

where $m_{c}$ is total weight of the machine, $\mathrm{kg} ; I_{c}$ is integral inertia of the machine relative to longitudinal axis passing through the machine mass centre, $\mathrm{kg} \cdot \mathrm{m}^{2}$; and $v$ is the machine velocity, $\mathrm{m} / \mathrm{s}$.

Potential energy of the system is implemented through air power within pneumatic wheels. It is:

$$
E_{P}=\frac{C_{w}}{2}\left(y-L_{k} \theta\right)^{2}+\frac{C_{w}}{2}\left(y-L_{k} \theta-h_{L}\right)^{2},
$$

where $C_{w}$ is radial stiffness of the machine pneumatic wheel, $\mathrm{N} / \mathrm{m} ; L_{k}$ is one-half of the machine wheel track, $\mathrm{m} ; h_{L}$ is a pitch of a left wheel of the continuous bridge on the sinusoidal profile irregularities, $\mathrm{m}$.

In general, height of the irregularity can be expresses as follows:

$$
h_{L}=h_{0} \sin \frac{2 \pi X}{L_{0}},
$$

where $h_{0}$ is amplitude value of a mine path profile irregularity, $\mathrm{m} ; x$ is an absciss approximating a function of floor irregularities, $\mathrm{m}$; and $L_{0}$ is length of a sinusoid approximating a function of floor irregularities, $\mathrm{m}$.

$x=v t$ if the machine moves; then a pitch of a right wheel is: 


$$
h_{L}=h_{0} \sin \frac{2 \pi X v}{L_{0}} t
$$

While neglecting nonconservative forces, we substitute (in the $y$ coordinate) the expression of kinetic and potential energy into Lagrange's equation of second kind (1). Thus, combining the obtained expressions, we form differential equation one:

$$
m_{c} \ddot{y}+2 C_{w} y=C_{w} h_{L} .
$$

To obtain differential equation two, we repeat the operation in the $\theta$ coordinate:

$$
m_{c} \ddot{\theta}+2 C_{w} L_{k}^{2} \theta=C_{w} L_{k} h_{L} .
$$

Rearrange equations (6) and (7) taking into consideration expression (5):

$$
\begin{aligned}
& m_{c} \ddot{y}+2 C_{w} y=C_{w} h_{0} \sin \frac{2 \pi v}{L_{0}} t ; \\
& I_{c} \ddot{\theta}+2 C_{w} L_{k}^{2} \theta=C_{w} L_{k} h_{0} \sin \frac{2 \pi v}{L_{0}} t .
\end{aligned}
$$

The addends, describing free vibrations of the load-haul-dumper, are determined relying upon the initial conditions; they almost nullify after a while. Forced vibrations remain. They are described as follows:

$$
\begin{gathered}
y=\frac{C_{w} h_{0}}{m_{c}\left|P_{y}^{2}-\frac{4 \pi^{2} v^{2}}{L_{0}^{2}}\right|} \sin \left(\frac{2 \pi v}{L_{0}} t-\psi_{1}\right) ; \\
\theta=\frac{C_{w} L_{k} h_{0}}{I_{c}\left|P_{\theta}^{2}-\frac{4 \pi^{2} v^{2}}{L_{0}^{2}}\right|} \sin \left(\frac{2 \pi v}{L_{0}} t-\psi_{2}\right) .
\end{gathered}
$$

After proper cyclic frequency replacing, we obtain a condition of LHD instability within a transverse plane during asymmetric disturbance:

$$
\frac{2 C_{w} L_{k}^{2}}{I_{c}}-\frac{4 \pi^{2} v^{2}}{L_{0}^{2}}=0 .
$$

Using equation (12) we obtain critical velocity $v_{D}$ when pneumatic-tire LHD with stiff suspension becomes unstable in the context of the disturbed motion within transverse plane:

$$
v_{D}=\frac{L_{k} L_{0}}{\pi} \sqrt{\frac{C_{w}}{2 I_{c}}} .
$$

Fig. 3 shows dependences of allowable LHD velocity in accordance with expression (13) after processing with the help of standard mathematical methods and approximation. 


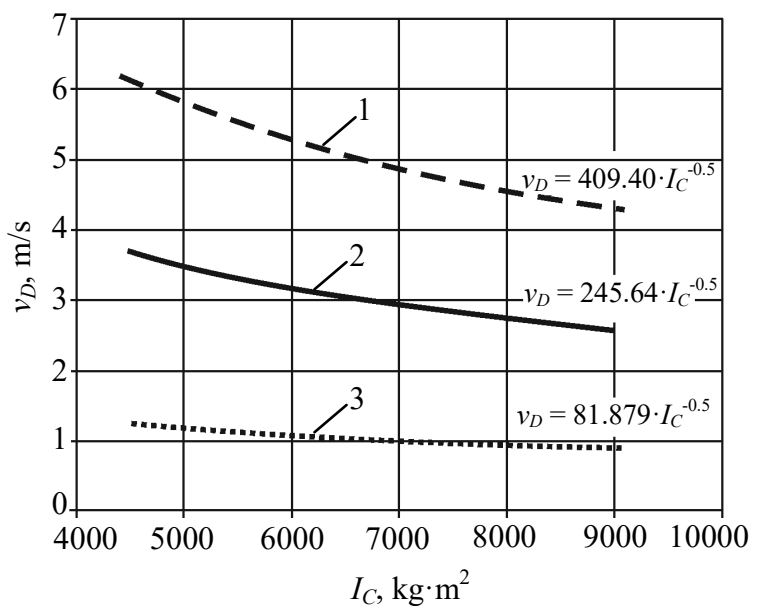

Fig. 3. Dependence of allowable LHD velocity in terms of various lengths sinusoidal wave approximating a function of road irregularities: $1-L_{0}=0.1 \mathrm{~m} ; 2-L_{0}=0.3 \mathrm{~m} ; 3-L_{0}=0.5 \mathrm{~m}$.

Fig. 3 demonstrates clearly the fact that in the context of the disturbed motion within transverse plane, allowable velocity of pneumatic-tired LHD with stiff suspension $\left(v_{D}\right)$ varies according to exponential law depending upon a value of inertia moment $\left(I_{c}-0.5\right)$.

\section{Conclusions}

The outcomes of the research have made it possible to analyze operation conditions of LHD, and their layout diagrams; moreover, the expediency to use the spaced scheme of pin-connected joints when rear and front sections are interconnected only by means of a lagging hinge. In this context, flapping hinge is applied for center-pin-supported rear axle. Layout features of the spaced pin-connected frame construction have been used to develop mathematical models of disturbed motion, if only antisymmetrical kinetic disturbances are available since they are the basis to select geometry of mine workings.

The developed mathematical models involve both static and dynamic criteria in the process of a mine working geometry selection; they are rated for the development of innovative self-propelled facilities while applying flexible suspension of continuous bridges and stabilizer bars.

Thus, operation parameters of LHD with flexible suspension, helping determine critical velocity within irregular-shaped underground mine workings, have been obtained.

The authors highly appreciate the assistance and consultations rendered by Vadym Kosarenko, Director of "Novokonstiantynivska" and "Smolinska" mines of "Skhidnyi hirnycho-zbahachuvalnyi kombinat" SE.

\section{References}

1. Khomenko, O., \& Maltsev, D. (2013). Laboratory research of influence of face area dimensions on the state of uranium ore layers being broken. Naukovyi Visnyk Natsionalnoho Hirnychoho Universytetu, 31-37.

2. Shirin, A., Rastsvetaev V., \& Morozova, T. (2012). Estimation of reliability and capacity of auxiliary vehicles while preparing coal reserves for stoping. Geomechanical Processes during Underground Mining: School of Underground Mining 2012, 105-108. https://doi.org/10.1201/b13157-18 
3. Shyrin, A., Rastsvetaiev, V., \& Inyutkin, I. (2017). Operativno-proizvodstvennoe upravlenie tekhnicheskim sostoyaniem transportno-tekhnologicheskikh skhem gornorudnykh predpriyatiy. Visnyk Kryvorizkoho Natsionalnoho Universytetu, 38-43.

4. Kovalevska, I., Symanovych, G., \& Fomychov, V. (2013). Research of stress-strain state of cracked coal-containing massif near-the-working area using finite elements technique. Annual ScientificTechnical Collection - Mining of Mineral Deposits, 159-163. https://doi.org/10.1201/b16354-28

5. Shirin, L., Korovyaka, Y., \& Tokar, L. (2011). Justification of design parameters of compact load-haul dumper to mine narrow vein heavy pitching deposits. Technical and Geoinformational Systems in Mining, 85-92. https://doi.org/10.1201/b11586-15

6. Bartashevski, S.E., Strashko, V.A., Shirin, L.N., \& Shumrikov, V.V. (2001). Mathematical Models of Work-cycle Time of Ladleman Loading Machine. Vibration in Methods and Technology, 3(19), 46-49.

7. Shirin, L., \& Iniutkin, I. (2009). Osobennosti formirovaniya transportno-tekhnologicheskikh sistem podzemnyh rudnikov s uchetom adaptatsionnykh vozmozhnostey samokhodnogo oborudovaniya. Naukovyi Visnyk Natsionalnoho Hirnychoho Universytetu, 66-68.

8. Shirin, L.N., Korovyaka, E.A., \& Shirin, A.L. (1998). Model Analysis of Adaptive Capacity of Load-haul Dumpers to Mine Narrow Vein Deposits. Inter-agency Collection of Scientific Papers of IGTM of the NAS of Ukraine, (6), 67-73.

9. Kalnitskiy, Ya. \& Filimonov, A. (1974). Samokhodnoe pogruzochnoe i dostavochnoe oborudovanie na podzemnykh rudnikakh. Moskva: Nedra.

10. Malinovskiy, E. \& Gaytsgori, M. (1974). Dinamika samokhodnykh mashin s sharnirnoy ramoy. Moskva: Mashinostroenie.

11. Beihul, O., \& Kolesnyk, I. (2011). Dynamika ta mitsnist metalurhiinykh mashyn. Dniprodzerzhynsk: Dniprodzerzhynskyi derzhavnyi tekhnichnyi universytet. 